\title{
Follow-up of 53 Alzheimer patients with the MODA (Milan Overall Dementia Assessment)
}

\author{
E. Capitani, L. Manzoni and H. Spinnler \\ Milan University, Third Clinic for Nervous Diseases, S. Paolo Hospital, Milan, Italy \\ Correspondence to: E. Capitani, Clinica Neurologica dell'Università di Milano, \\ Ospedale S. Paolo, via A. Di Rudinì 8, 20142 Milano, Italy
}

\begin{abstract}
Fifty-three patients affected by Alzheimer's disease entered a longitudinal survey aimed at studying which factors influence the rate of progression, assessed by means of the Milan Overall Dementia Assessment (MODA). The second examination was carried out, on average, after 16 months from the first assessment. Only age proved to influence the decline rate, which was faster in elders.
\end{abstract}

Keywords: Alzheimer's disease - Psychometrics.

This article originally appeared in European Journal of Neurology (1997), 4, 237-239.

\section{INTRODUCTION}

The natural history of patients affected by dementia of Alzheimer type (DAT) is receiving increasing attention. Some investigators have published surveys following a neuropsychological approach (Haxby et al., 1992), whereas other studies have focused on structural aspects, such as the neuroradiological quantification of brain atrophy.

The real impact of these studies on the biological and clinical knowledge of DAT is still under scrutiny. Some authors have presumed a strict parallelism between the laws governing the decline of psychometric measures and that of the underlying biological phenomenon. However, the debate on the measurement scales of psychological and behavioural tools (Townsend and Ashby, 1984) should not be neglected and great caution is needed when evaluating studies in which neuropsychological or behavioural instruments are credited with interval properties. In any case, these inferences depend on the availability of at least three or four longitudinal evaluations of the same patient (Helmes et al., 1995).

Even admitting a subtle indeterminacy between the biological and the psychometric/behavioural domains, the longitudinal study of DAT patients can still be useful. For instance, if a psychometric scale is used to assess the efficacy of a treatment, we might wonder whether the expected decline of our patients with that measure significantly depends on the initial cognitive level, as this would introduce noise in the treatment evaluation and suggest a sample stratification for initial severity. Moreover, if any significant differences were due to treatment, only the determination of the temporal rate of natural decline would enable us to convert raw psychometric data into the slowing of the tempo of disease progression.

In this survey we report a longitudinal study of 53 DAT patients who were given two examinations with the MODA (Milan Overall Dementia Assessment, Brazzelli et al., 1994). Our aim was to study the natural rate of decline and the factors that may influence it, as well as to add further information to the MODA database.

\section{SUBJECTS AND METHODS}

The MODA is a neuropsychologically-oriented test designed to assess dementia. Normative data, adjusted for age and education, were derived from 217 controls. The test yields a total score of 100 points and is subdivided into three sections: neuropsychological tests (50 points), orientation (35 points) and autonomy (15 points). The neuropsychological section includes the easiest items from some formal, currentlyemployed tests in order to avoid a floor effect in severe 
patients. The orientation inquiry includes temporal, spatial, personal and family orientation, and the autonomy scale investigates five aspects of everyday living: walking; dressing; personal hygiene; sphincter control; and eating. Further details can be found in the original paper. The inferentially-controlled threshold under which we expect to find less than $5 \%$ of the general population is 85.5 (after adjustment for age and education).

In this survey we studied 53 patients diagnosed as having DAT on the basis of the DSM-III-R and NINCDS-ADRDA criteria. This sample was drawn from a consecutive series of 154 subjects affected by DAT who were observed in our neurogeriatric outpatient units from December 1986 to December 1994. In this survey we considered only patients with a first overall MODA score greater than 40, who were examined again after an interval ranging from 6 to 48 months.

The individual rate of decline of the total MODA scale was calculated as a ratio between (1) the difference between the first and the second examination; and (2) the interval (in months) between the two examinations. An approximate age at onset of DAT was also estimated by considering when the symptoms of mental decline were first noticed either by the patient or by their relatives. A quantitative description of the sample is reported in Table I.

\section{RESULTS}

The average rate of decline was of 1.15 points/month, with an S.D. of 0.99 . Factors that may potentially influence the progression were studied by means of a regression analysis (for the continuous variables) or

TABLE I. Sample studied in this survey

\begin{tabular}{ll}
\hline Age at testing & $69.0 \pm 9.8$ (range 51-92) \\
& $24 / 53$ patients older than \\
& 70 years \\
& $7.5 \pm 3.9$ \\
Education & 14 males and 39 females \\
Gender & $68.5 \pm 15.7$ \\
MODA (first examination) & $49.6 \pm 22.4$ \\
MODA (second examination) & $18.9 \pm 15.9$ \\
MODA (difference) & $16.1 \pm 9.7$ (range 6-48) \\
Interval between first and & $9 / 53$ patients $>24$ \\
second & (months) \\
MODA examination (months) & $39.9 \pm 24.6$ \\
& \\
Length of symptoms (months) & \\
Average estimated age of DAT & $65.8 \pm 10.0$ \\
onset & $1.15 \pm 0.99$ \\
Average MODA monthly & \\
decline & \\
\hline
\end{tabular}

TABLE II. Factors influencing DAT progression

\begin{tabular}{ll}
\hline Source of Variability & Statistical Analysis \\
\hline Age at testing & $F(1,51)=5.821, \mathrm{p}=.012$ \\
Age at onset & $F(1,51)=6.812, \mathrm{p}=.012$ \\
Education & $F(1,51)=1.270, \mathrm{~N} . \mathrm{S}$. \\
Gender & $t(51)<1, \mathrm{~N} . \mathrm{S}$. \\
Length of symptoms & $F(1,51)=1.170, \mathrm{~N} . \mathrm{S}$. \\
Moda score at first examination & $F(1,51)<1, \mathrm{~N} . \mathrm{S}$. \\
Interval between first and second & $F(1,51)<1, \mathrm{~N} . \mathrm{S}$. \\
MODA examination & \\
\hline
\end{tabular}

N.S. = not significant.

Student's $t$-test (for the categorical variables). We investigated the effects of the following: age at testing; age at onset; education; gender; the time between the first symptoms and the first examination; the MODA severity at the first examination; and the interval between first and second examination (Table II). Age at testing proved to be significantly influential on the decline rate $(F=5.821, \mathrm{df}=1,51, p=0.019)$, pointing to a greater decline in the older subjects; the same outcome was observed when the estimated age of onset was considered as the independent variable $(F=6.813, \mathrm{df}=1.51, \quad p=0.012)$. The average monthly decline was $0.90 \pm 0.91$ until 70 years of age at testing, and $1.46 \pm 1.02$ thereafter. Subdividing the patients according to the presence of other DAT cases in their family (familial cases were 19) did not reveal a different progression rate (1.22 point/month in the non-familial cases, versus 1.03 in the familial ones, Student's $t<1$, N.S.).

\section{DISCUSSION}

Results of longitudinal studies may be contingent on the rating scales actually employed in each survey. In the case of MODA, the rate of progression was fairly constant and neither depended on the initial severity nor on the interval between the first and the second examination.

The only significant effect was played by the age of the patient, both at testing and at the estimated onset of DAT. The lack of significant influence of baseline level makes it unlikely that our finding was flawed by potential artefacts linked to basic differences in the severity of patients of different ages. Patients aged over 70 were slightly less severe at onset (MODA $=64.9$ \pm 14.3 ) with respect to those younger than 70 (MODA $=71.5 \pm 16.3$ ), although this was not a significant difference $(t=1.565, \mathrm{df}=51$, N.S.).

Our conclusion is at variance with those suggesting a more severe progression of dementia in younger 
patients (Lorin and Largen, 1987; Lucca et al., 1993), as well as with those who have failed to find an ageeffect (Huff et al., 1987; Katzman et al., 1988; Bracco et al., 1994). There are, however, a number of differences across the studies on this topic. Besides the heterogeneity of the target measures registered in different surveys, inclusion criteria and sampling were different: most studies adhered to a cross-sectional design, and this strategy entails a greater risk of sampling bias with respect to the longitudinal approach followed in the present study. Interestingly, even in our sample a crosssectional analysis showed a trend toward a greater severity of younger patients, but the progression was faster in the older subjects. A greater severity of younger patients in cross-sectional studies (Capitani et al., 1990) does not appear to imply that their deterioration is faster when explicitly tested in a longitudinal study. Longitudinal findings with a strictly neuropsychologically- oriented global score such as the MODA are likely to provide a more reliable measure of the cognitive decline of DAT patients.

\section{REFERENCES}

Bracco L, Gallato R, Grigoletto F et al. (1994) Factors affecting course and survival in Alzheimer's disease. Archives of Neurology, 51, 1213-1219.

Brazzelli M, Capitani E, Della Sala S, Spinnler H and Zuffi M (1994) A neuropsychological instrument adding to the description of patients with suspected cortical dementia: the Milan Overall Dementia Assessment. Journal of Neurology, Neurosurgery and Psychiatry, 57, 1510-1517.

Capitani E, Della Sala S and Spinnler H (1990) Controversial neuropsychological issues in Alzheimer's disease. Cortex, 26, 133-145.

Haxby JV, Raffaele K, Gillette J, Schapiro MB and Rapoport SI (1992) Individual trajectories of cognitive decline in patients with dementia of the Alzheimer type. Journal of Clinical and Experimental Neuropsychology, 14, 575-592.

Helmes E, Merskey H, Fox H, Fry R, Bowler J, Hashinski $\mathrm{V}$ (1995) Patterns of deterioration in senile dementia of Alzheimer type. Archives of Neurology, 52, 306-310.

Huff FJ, Growdon JH, Corkin S et al. (1987) Age at onset and rate of progression in Alzheimer's disease. Journal of American Geriatric Society, 35,27-30.

Katzman R, Brown T, Thal LJ et al. (1988) Comparison of rate of annual change of mental status score in four independent studies of patients with Alzheimer's disease. Annals of Neurology, 24, 384-389.

Lorin DW and Largen JW (1987) Neuropsychological pattern of presenile dementia of Alzheimer type. Neuropsychologia, 23, 351-357.

Lucca U, Comelli M, Tettamanti M et al. (1993). Rate of progression and prognostic factors in Alzheimer's disease: a prospective study. Journal of American Geriatric Society, 41, 45-49.

Townsend JT and Ashby FG (1984) Measurement scales and statistics: the misconception misconceived. Psychological Bulletin, 96, 394-401.

(Received 11 July 1996; accepted as revised 23 December 1996) 


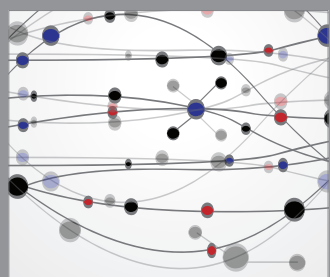

The Scientific World Journal
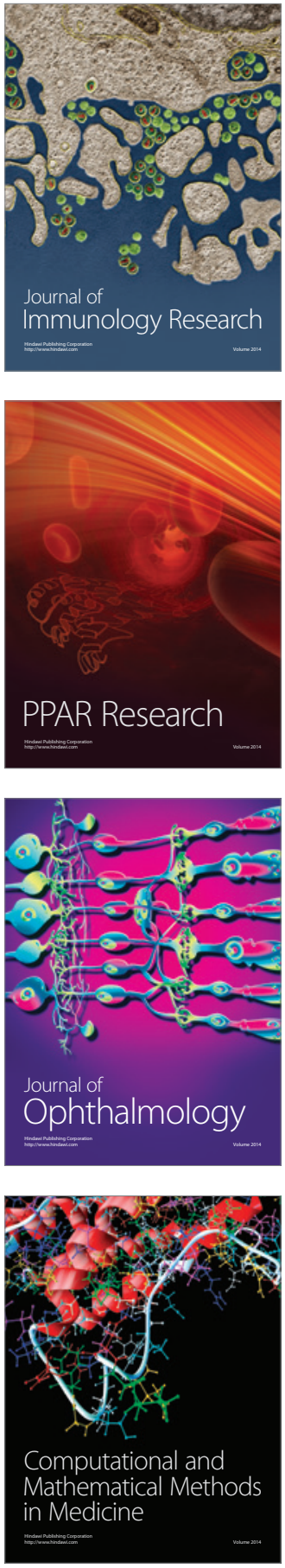

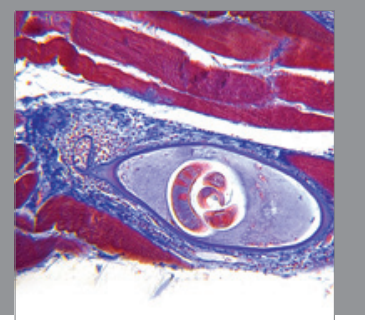

Gastroenterology

Research and Practice
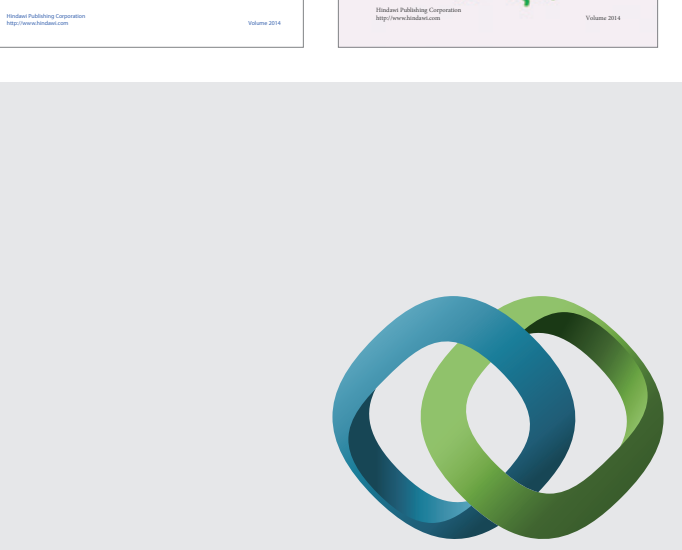

\section{Hindawi}

Submit your manuscripts at

http://www.hindawi.com
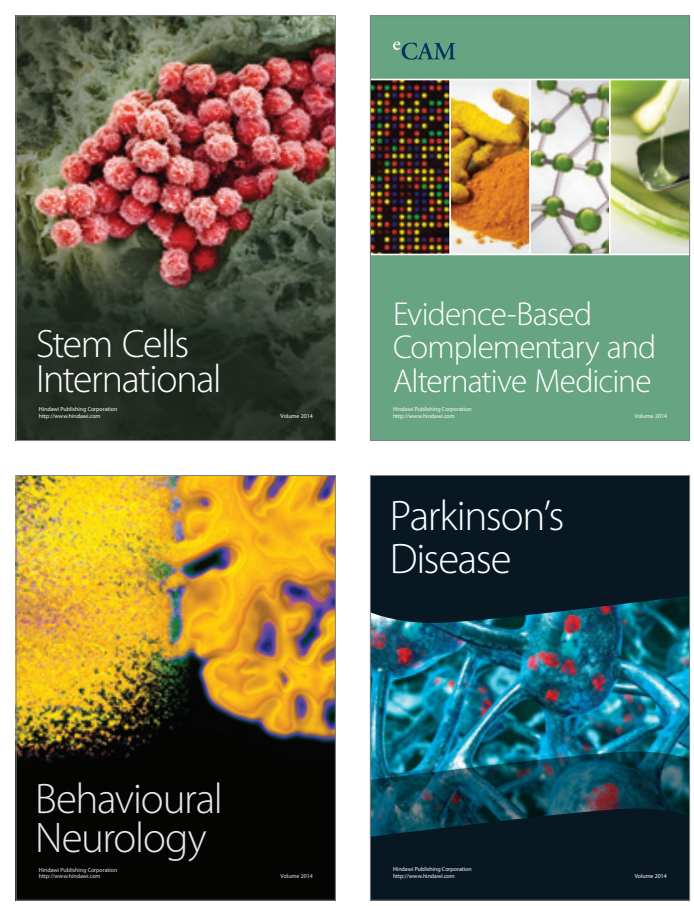

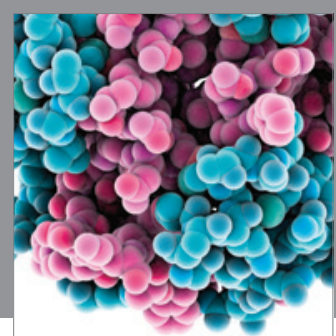

Journal of
Diabetes Research

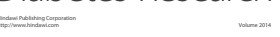

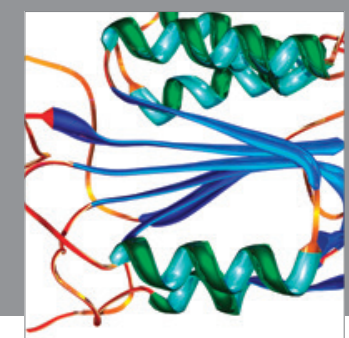

Disease Markers
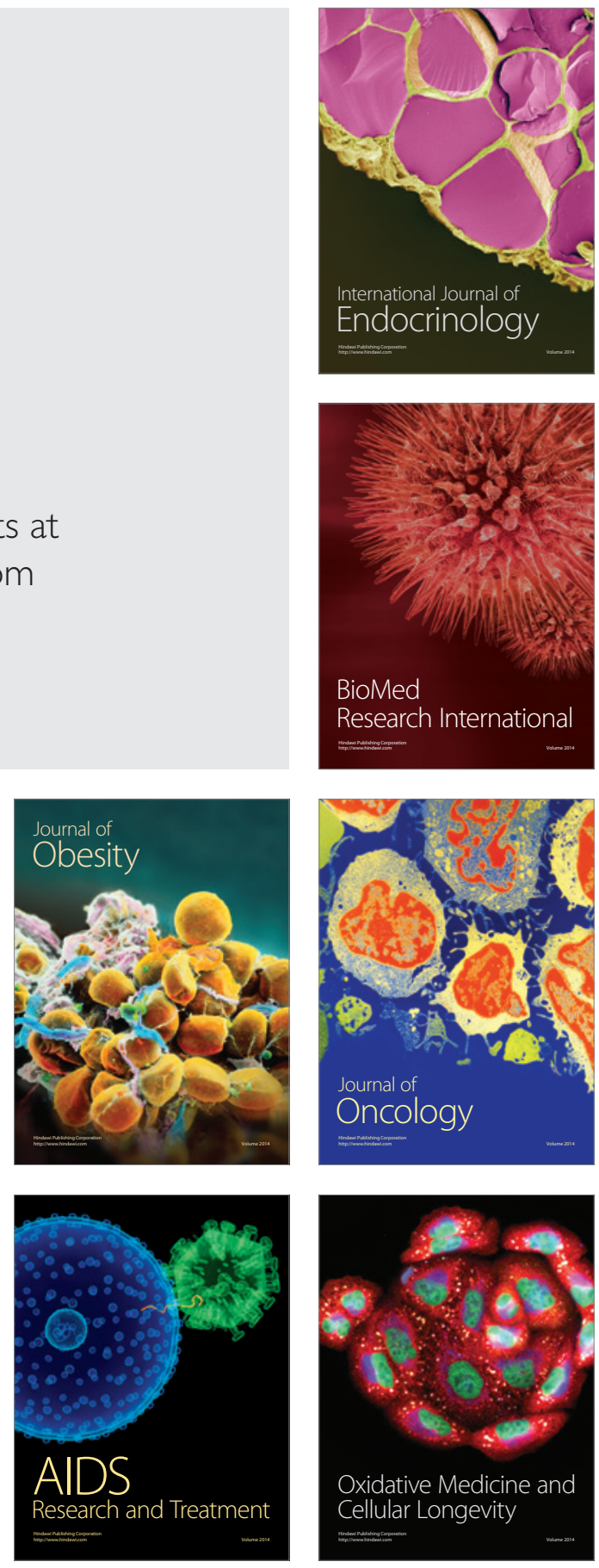